\title{
Epilepsy and Child History in Dr. Jamal Ahmad Rashid Pediatric Teaching Hospital Sulaymaniyah /Iraq
}

\author{
Awayi Ghazy Abdulkareem \\ Pediatric Department \\ College of Nursing \\ University of Sulaimani \\ Sulaimani, iraq \\ awayi.abdulkareem@univsul.edu.iq
}

\section{Article Info \\ Volume 6-Issue 2- \\ December 2021 \\ DOI: \\ 10.24017/science.2021.2.11}

Article history:

Received 25/10/2021

Accepted 24/1/2022

\section{Keywords:}

Epilepsy , children, history, risk factors, neurological disorder

\begin{abstract}
Epilepsy is a chronic neurological illness that is the most prevalent severe brain problem worldwide. The purpose of this research is to determine the importance of certain risk variables for epilepsy in children in Sulaymaniah City, such as age, gender, head trauma, nervous system infectious diseases including meningitis and unusual perinatal history, low birth weight, neonate respiratory failure, neonatal seizure, socioeconomic status, as well as parent consanguinity. This research was created based on 104 cases (where 51 of the patients were male, while 53 of the patients were female) among the inpatient and outpatient neurology unit of Dr Jamal Ahmad Rashid Pediatric Teaching Hospital from 20/12/2020 to 29/4/2021. In this research, all the children were evaluated, as well as their medical and personal information was collected. A relation between the phenomenon of epilepsy with numerous risk factors was made; the ratio was calculated to determine the essential variables linked with epilepsy. Data were collected through interviewing of the patients then analyzed through the application of statistical analysis descriptive. As a result of the study each of Age, head trauma, gender, febrile, positive family history for epilepsy, unusual perinatal history, and neonatal infection has been shown to have a statistically significant link to epilepsy.
\end{abstract}

Copyright $@ 2021$ Kurdistan Journal of Applied Research. All rights reserved.

\section{INTRODUCTION}

Epilepsy is a brain illness that produces seizures in children. This is among the most prevalent nervous system illnesses, affecting adults $\&$ children of whole races and ethnic origins. As a burst of aberrant electric signals disrupts the normal brain signals, a seizure occurs; everything that disrupts the normal regular connections among nerve cells in the brain could trigger a seizure. These contain a high temperature, low or high blood sugar, alcohol or other drug 
withdrawals, or a head injury. Epilepsy, on the other hand, is diagnosed when a child has two or more seizures without a known cause [1].

In most population-based epilepsy epidemiology research, two or more seizures occurring at least 24 hours apart are defined as epilepsy."; in theory, an epileptic seizure is described as "a brief appearance of signs and/or symptoms caused by abnormally high or synchronous neuronal activity in a brain' [2].

As a result, epilepsy is currently the most common childhood brain condition, and it is a brain disorder that causes an infant to suffer from recurring seizures. The electrical and chemical activation of the brain are both altered, which causes seizures, seizures could be influenced by everything that damages the brain, such as brain injuries, infections, poisoning, and even development of the brain issues before birth. Generally, the causes of the seizures as well as epilepsy could not be identified. [2].

Epilepsy is caused by many reasons. Common causes of childhood seizures or epilepsy include Fever (febrile seizures), genetics, head trauma, infections of the head and its covering, lack of oxygenated blood, hydrocephalus (excess water in the brain canals), and brain developmental anomalies [3].

Seizures are based on a combination of genetic and cultural factors in each person; inheritance is highly significant as a cause of epilepsy; epilepsy was also regarded as a mainly inherited illness in the nineteenth century, generally as one symptom of the 'neurological trait'. as well as provoking elements, despite the complex nature of causation, instances could be divided into four groups based on the primary cause (or presumed reason).

Idiopathic epilepsy is recognized as epilepsy that is mostly genetic in the origin, so that it has no substantial neuroanatomical or neuropathological abnormalities. A single gene such as KCNQ2 produces a few uncommon epilepsies; more widespread are epilepsies via polygenic or complicated inheritance. Many 'idiopathic generalized epilepsies' including 'benign epilepsies of children' fall into to this group. The word idiopathic is selected since the epilepsy is caused by a complicated mix of likely genetic and non-genetic pathways, including epigenetic and epistatic pathways, via chance and environmental factors acting throughout time as the brain grows. Symptomatic epilepsy is described as epilepsy that is caused by an inherited or genetic origin and linked via neuroanatomical or neuropathological abnormalities indicating an underlying illness or condition. This group involves acquired diseases and developmental and congenital illnesses that are linked with pathological brain alterations, whether genetic (acquired) in the origin [4].

Certain 'provoked epilepsies' will also have a genetic foundation, while others will have an acquired base. This group includes reflex epilepsies (that are generally genetic) and epilepsies with such a strong seizure precipitant. Cryptogenic epilepsy is described as epilepsy of suspected symptomatic origin where the reason has not been determined. The numerous of all such instances is decreasing. However, it remains an influential group, accounting for at least 40percentage points of adult-onset [5].

They have been assumed to be the outcome of a genetic predisposition or a one-of-a-kind style of inheritance. Symptomatic epilepsies are thought to be caused by a localized or diffused brain lesion, as confirmed by history taking, functional neuroimaging, EEG (human electroencephalogram) results, or biological tests [5]. Seizures that are partial (focal, local): Simple partial seizures (without loss of consciousness): through motor indications, sensorial signals, autonomic symptoms or signs, psychic signs, and so on [6].

Complex partial seizures (via impairment of consciousness), simple partial-onset guided by impairments of consciousness: via simple partial parts followed by impaired consciousness, automatisms, via impairment of consciousness at the beginning, partial seizures proceeding to secondary generalised seizures, simple partial seizures progressing to generalised seizures, complex partial seizures progressing to generalised seizures that are widespread: Myoclonic seizures, clonic seizures, tonic-clonic seizures, atonic seizures, and tonic seizures are the most common types of seizures [7].

CAE is a common IGE that affects otherwise healthy school-aged teenagers. The clinical picture is one of frequent absence seizures. Inter-ictal EEG demonstrates natural background 
activities and generalised three $\mathrm{Hz}$ spike-and-wave discharge, which transforms into a clinical seizure after 4-5 seconds. A diagnosis is made by identifying the condition based on symptoms and signs. Seizures with no apparent cause, such as fever or trauma, are frequently diagnosed as epilepsy. While the diagnostic process for each child may vary, the following phases are often included: Parents with epilepsy may be asked questions concerning their child's high fever, serious head injury, staring, inattention, or breath-holding.

A detailed seizure report: The person(s) present during the child's seizure will be interviewed. Computed tomography (CT) scan: A CT scan can assess whether an acute brain lesion or disease causes a seizure. EEG: This could be used to predict seizure recurrence risk and identify seizure types and epilepsy syndromes. Brain picture recommended for analyzing teenagers with new-onset seizures or seizures that started in a specific location of the brain. An epilepsy diagnosis is made after an examination, testing, and observation period [8]. On average, $0.5-1 \%$ of adolescents have epilepsy, making it the most frequent chronic neurologic condition in infancy. Epilepsy symptoms are important for parents, educators, and other caregivers. Notably, many of these symptoms are characteristic of childhood. Even if they are frequent and uncommon, it is crucial to remember that seizures are not invariably epilepsy. High fevers and many illnesses can trigger seizures. Attention span, memory, muttering, or no reply, unanticipated stomach ache with disorientation and lethargy, unanticipated abnormal tiredness with irritation when awoken. rapid and recurrent fear or anger Clusters of seated babies "jackknifing" and clusters of neonates clutching with both arms [9].

\section{METHODS AND MATERIALS}

\subsection{The Research Design}

The Quantitative (descriptive study) is a purposive design used to find out the "Prevalence of Some of Risk Factor among Children with Epilepsy in Sulaymaniah City". The study was carried out from $2^{\text {nd }}$ February 2021 till $18^{\text {th }}$ March 2021.

\subsection{Administration Arrangement and Ethical Considerations}

Official permission was obtained from Dr. Jamal Ahmad Rashid Pediatric Teaching Hospital / chronic disease department for this study was granted after verbal informed consent was achieved from whole participants before their involvement in this research to gain their confidence and acceptance to participate in the current study.

\subsection{The setting of the research}

This research was carried out at Dr. Jamal Ahmad Rashid Pediatric Teaching Hospital, founded in 1970 to serve children and located in Sulaimaniah City. The sample of this study taken in the chronic disease department, it was a daily based patient department, this centre founded in 2014 every month more than 300 children after diagnosed with a chronic disease. like (Epilepsy, mental growth retardation,) of neonate till 18 years old they visiting this center. for receiving chronic medication, follow up, checking. This department consists of staff that specializes in dealing with a child with chronic disease.

\subsection{Sample of the research}

The non-probability essential sampling was used, a sample of (104) children via epilepsy who attend the chronic disease department in Dr. Jamal Ahmad Rashid Pediatric Teaching Hospital, The Children were chosen according to the following criteria:

\subsubsection{Inclusion criteria}

1. Whole children with epilepsy.

2. Children aged less than 18 years old.

3. Children registered in the chronic center in Dr. Jamal Ahmad Rashid pediatric teaching hospital.

4. Children and their parents who have voluntarily accepted to participate in this research and consent were given.

\subsubsection{Exclusion criteria}


1. Children who do not have epilepsy

2. Children who mentally retarded

3. Children and their families who refuse to participate

4. For the present study child with other chronic diseases

2.5. The study instrument

A questionnaire was developed mainly to find the "Some Risk Factors Prevalence among Children with Epilepsy in Sulaymaniah City". The development of the questionnaire is based on some intensive review of available literature and measurement tool and questionnaire used in previous related studies. The questionnaire includes two parts. The first part is sociodemographic characteristics of the child, which includes age, gender, child order in the family, children at diagnosis, residency, one of seizure age, seizure types, when was the last attack of seizure, has your child ever been hospitalized for seizure, gestational age, type of delivery, place of delivery, low birth weight, did the child have any head abnormality, neonatal jaundice pathologic, head trauma, febrile convulsion, neonate respiratory failure, infection neonate period, admitted to NICU, and neonatal seizure. The second part is the family's sociodemographic characteristics, including a family history of epilepsy, parent consanguinity, mother's chronic disease, mother's age at birth, and whether the mother was under any medication during pregnancy.

\subsection{Validity of Questionnaire Form}

The face validity of a present study questionnaire was established through the panel of (13) experts. The specialists were requested to assess the questionnaire for content clarity, relevancy, and appropriateness to accomplish the research objectives.

\subsection{Pilot Study}

A pilot research was conducted on the unpurposive Sample of 10 epilepsy children from 15 January to 25 of January 2021. Pilot research aims to evaluate the instrument's reliability, assess the instrument's clarity, and estimate the average time required for data collection. According to the outcomes of the pilot research time required for the interview ranged between 25 to 30 minutes for each respondent. On the other hand, Cronbach's alpha values were estimated to check the internal accuracy of data depending on reliability test which it is a scale tool of reliability $[10,12]$. In this pilot study, the reliability result based on Alpha Cronbach result on 10 children is 0.89 It passes the reliability analysis $\alpha$-value greater than the acceptable minimum value of Cronbach's alpha [11, 14].

\subsection{Statistical Procedures}

Data were prepared, organized, and entered into the program named Statistical Package for Social Service (SPSS, version 23). In this study, descriptive Statistics were found for all demographic questions [15]. Chi-Square tests were also utilized to determine the association between children's social and parents' demographics [13, 11]. The Chi-square test of independence is a famous nonparametric test for determining whether at least two categories of samples are independent or not. A common question about a contingency table is whether it is independent. Independence indicates the absence of any link among row and column parameters (The quantity of a row variable would not help us guess the value of a column variable) [16]. The null theory implies that understanding the level of variable A does not assist you to anticipate the level of variable B (There is no connection between two variables). In contrast, the alternative theory is that there is a link between two variables. The null, as well as alternative hypotheses, are stated in chi-square tests of independence [11]:

H0: The two categorical variables are unrelated to one another.

Ha: The two categorical variables are related.

\section{RESULTS}

Table 1 represents the children's socio-demographic characteristics, including age, gender, child order, age of diagnosis, and residency.

The result showed that most children are aged between six to ten $(36.5 \%)$ while most are diagnosed between ages one to five $(46.2 \%)$. The percentage of females $(51 \%)$ is higher than 
the percentage of males (49\%) since most of them are living in urban $(67 \%)$. Second-order child is the most percentage in the family $(33.7 \%)$ followed by third $(28.8 \%)$, first $(16.3 \%)$, fourth $(15.4 \%)$, and fifth $(5.8 \%)$ respectively.

Table 1: Socio Demographic Questions of the Children

\begin{tabular}{|c|c|c|c|}
\hline & & Frequency & Percentage (\%) \\
\hline \multirow[t]{4}{*}{ Age } & $1-5$ & 23 & $22.1 \%$ \\
\hline & $6-10$ & 38 & $36.5 \%$ \\
\hline & $11-15$ & 35 & $33.7 \%$ \\
\hline & $16-20$ & 8 & $7.7 \%$ \\
\hline \multirow[t]{2}{*}{ Gender } & Male & 51 & $49.0 \%$ \\
\hline & Female & 53 & $51.0 \%$ \\
\hline \multirow{5}{*}{$\begin{array}{l}\text { Child order } \\
\text { in the family }\end{array}$} & First & 17 & $16.3 \%$ \\
\hline & Second & 35 & $33.7 \%$ \\
\hline & Third & 30 & $28.8 \%$ \\
\hline & Fourth & 16 & $15.4 \%$ \\
\hline & Fifth & 6 & $5.8 \%$ \\
\hline \multirow{4}{*}{$\begin{array}{l}\text { Children age } \\
\text { at diagnosis }\end{array}$} & $1-5$ & 48 & $46.2 \%$ \\
\hline & $6-10$ & 37 & $35.6 \%$ \\
\hline & $11-15$ & 15 & $14.4 \%$ \\
\hline & $16-20$ & 4 & $3.8 \%$ \\
\hline \multirow[t]{3}{*}{ Residency } & Rural & 32 & $31.1 \%$ \\
\hline & Suburban & 3 & $1.9 \%$ \\
\hline & Urban & 69 & $67.0 \%$ \\
\hline
\end{tabular}

Table 2 represents the socio-demographic characteristics of the children about seizure. The onset of seizure age between one to five years old is the highest percentage among other ages (47.1\%) followed by 6 to $10(34.6 \%), 11$ to $15(14.4 \%)$ and 16 to $20(3.8 \%)$, respectively, while type for most of them are Generalized Seizure (71.2\%). Majority of the children who were attacked by last seizure in $2020(51.9 \%)$ while most of them have not been hospitalized for a seizure $(78.8 \%)$

Table 2: Socio-Demographic Characteristics of the Children about the seizure

\begin{tabular}{|c|c|c|c|}
\hline & & Frequency & Percentage (\%) \\
\hline \multirow[t]{4}{*}{ The onset of seizure age } & $1-5$ & 49 & $47.1 \%$ \\
\hline & $6-10$ & 36 & $34.6 \%$ \\
\hline & $11-15$ & 15 & $14.4 \%$ \\
\hline & $16-20$ & 4 & $3.8 \%$ \\
\hline \multirow[t]{3}{*}{ Seizure types } & Generalized Seizure & 74 & $71.2 \%$ \\
\hline & Focal Seizure & 29 & $27.9 \%$ \\
\hline & Unknown & 1 & $1.0 \%$ \\
\hline \multirow{6}{*}{$\begin{array}{l}\text { When was the last attack of } \\
\text { seizure? }\end{array}$} & 2016 & 1 & $1.0 \%$ \\
\hline & 2017 & 2 & $1.9 \%$ \\
\hline & 2018 & 4 & $3.8 \%$ \\
\hline & 2019 & 29 & $27.9 \%$ \\
\hline & 2020 & 54 & $51.9 \%$ \\
\hline & 2021 & 14 & $13.5 \%$ \\
\hline \multirow{2}{*}{$\begin{array}{l}\text { Has your child ever been } \\
\text { hospitalized for a seizure }\end{array}$} & Yes & 22 & $21.2 \%$ \\
\hline & No & 82 & $78.8 \%$ \\
\hline
\end{tabular}

Table3 represents the socio-demographic characteristics of the children at birth. Results showed that most children $(88.5 \%)$ who participated in this research responded NVD while most were at the hospital $(98.1 \%)$. The highest percentage of children had low weight during 
birth $(93.3 \%)$ and $96.2 \%$ of them had no head abnormality and $93.3 \%$ have no head trauma. The percentage of having no pathological jaundice at birth $(94.2 \%)$ are higher than children who had pathologic (5.8\%). In contrast, most children $(65.4 \%)$ had no febrile convulsion and had no neonate respiratory failure $(94.1 \%)$.

In addition, the majority of children had no infection $(92.3 \%)$ since fewer of them had admitted to NICU $(25 \%)$.

Table 3: Socio-Demographic Characteristics of the Children about birth

\begin{tabular}{|c|c|c|c|}
\hline & & Frequency & Percentage $(\%)$ \\
\hline \multirow[t]{3}{*}{ Gestational age } & Preterm & 5 & $4.8 \%$ \\
\hline & Mature & 98 & $94.2 \%$ \\
\hline & Post term & 1 & $1.0 \%$ \\
\hline \multirow[t]{2}{*}{ Type of delivery } & NVD & 92 & $88.5 \%$ \\
\hline & CS & 12 & $11.5 \%$ \\
\hline \multirow[t]{2}{*}{ Place of delivery } & Home & 2 & $1.9 \%$ \\
\hline & Hospital & 102 & $98.1 \%$ \\
\hline \multirow[t]{2}{*}{ Low birth weight } & Yes & 7 & $6.7 \%$ \\
\hline & No & 97 & $93.3 \%$ \\
\hline \multirow[t]{4}{*}{ head abnormality } & No & 100 & $96.2 \%$ \\
\hline & Sturge weber syndromes & 1 & $1.0 \%$ \\
\hline & Hydro cephalous & 1 & $1.0 \%$ \\
\hline & microcephaly & 2 & $1.9 \%$ \\
\hline \multirow{2}{*}{$\begin{array}{l}\text { Neonatal jaundice } \\
\text { (pathologic) }\end{array}$} & Yes & 6 & $5.8 \%$ \\
\hline & No & 98 & $94.2 \%$ \\
\hline \multirow[t]{2}{*}{ Head trauma } & Yes & 7 & $6.7 \%$ \\
\hline & No & 97 & $93.3 \%$ \\
\hline \multirow[t]{2}{*}{ Febrile convulsion } & Yes & 36 & $34.6 \%$ \\
\hline & No & 68 & $65.4 \%$ \\
\hline \multirow{2}{*}{$\begin{array}{l}\text { Neonate respiratory } \\
\text { failure }\end{array}$} & Yes & 6 & $5.9 \%$ \\
\hline & No & 96 & $94.1 \%$ \\
\hline \multirow{5}{*}{$\begin{array}{l}\text { Infections neonate } \\
\text { period }\end{array}$} & no infection & 96 & $92.3 \%$ \\
\hline & tonsillitis & 1 & $1.0 \%$ \\
\hline & dermatitis +UTI & 1 & $1.0 \%$ \\
\hline & UTI & 3 & $2.9 \%$ \\
\hline & Flu & 3 & $2.9 \%$ \\
\hline \multirow[t]{2}{*}{ Admitted to NICU } & Yes & 26 & $25.0 \%$ \\
\hline & No & 78 & $75.0 \%$ \\
\hline
\end{tabular}

Table4 represents the socio-demographic characteristics of parents. Most of the parents have negative epilepsy $(80.8 \%)$ and have no consanguinity $(81.7 \%)$. The majority of parents have no chronic disease $(97.1 \%)$ and most of them were aged between 20 and $25(30.8 \%)$. In addition, most of the parents used DM medication during parents (95.2\%).

Table 4: Socio-Demographic Characteristics about Parents

\begin{tabular}{llcc}
\hline & & \multicolumn{3}{c}{ Frequency } & Percentage(\%) \\
\hline Family history of & Positive & 20 & $19.2 \%$ \\
\cline { 2 - 4 } epilepsy & Negative & 84 & $80.8 \%$ \\
\hline Parent & No & 85 & $81.7 \%$ \\
consanguinity & Other relatives & 19 & $18.3 \%$ \\
\hline $\begin{array}{l}\text { Mother chronic } \\
\text { disease }\end{array}$ & no chronic disease & 101 & $97.1 \%$ \\
\cline { 2 - 4 } & heart disease +HTN & 1 & $1.0 \%$ \\
\cline { 2 - 4 } & heart disease +D.M & 1 & $1.0 \%$ \\
\cline { 2 - 4 } & HTN & 1 & $1.0 \%$ \\
\hline
\end{tabular}




\begin{tabular}{llcc}
\hline Mother age at birth & $20-25$ & 32 & $30.8 \%$ \\
\cline { 2 - 4 } & $26-30$ & 26 & $25.0 \%$ \\
\cline { 2 - 4 } & $31-35$ & 25 & $24.0 \%$ \\
\cline { 2 - 4 } & $36-40$ & 15 & $14.4 \%$ \\
\cline { 2 - 4 } & $41-45$ & 6 & $5.8 \%$ \\
\hline hypertension (heart disease) & 4 & $3.8 \%$ \\
\cline { 2 - 4 } $\begin{array}{l}\text { under any } \\
\text { medication during } \\
\text { pregnancy }\end{array}$ & drugs for DM & 1 & $1.0 \%$ \\
\cline { 2 - 4 } & drugs for thyroid & & \\
\hline
\end{tabular}

Table 5 showed a statistically significant association between febrile convulsion and family history of epilepsy depending on (Chi-Square value $=4.21$ and $\mathrm{P}$-value=0.032).

Table 5: Association between febrile convulsion and family history of epilepsy using Chi-Square test

\begin{tabular}{|c|c|c|c|c|c|c|}
\hline & & \multicolumn{2}{|c|}{$\begin{array}{c}\text { Family history of } \\
\text { epilepsy }\end{array}$} & \multirow[t]{2}{*}{ Total } & \multirow[t]{2}{*}{$\begin{array}{l}\text { Chi-Square } \\
\text { value }\end{array}$} & \multirow[t]{2}{*}{ P-value } \\
\hline & & Positive & Negative & & & \\
\hline \multirow[t]{2}{*}{ Febrile convulsion } & Yes & 3 & 33 & 36 & \multirow[t]{3}{*}{4.21} & \multirow[t]{3}{*}{0.032} \\
\hline & No & 17 & 51 & 68 & & \\
\hline Total & & 20 & 84 & 104 & & \\
\hline
\end{tabular}

Table 6 showed a statistically significant association between hospitalized for a seizure and parent consanguinity depending on (Chi-Square value $=6.118$ and $\mathrm{P}$-value $=0.019$ ).

Table 6: Association between hospitalized for a seizure and parent consanguinity using Chi-Square test

\begin{tabular}{|c|c|c|c|c|c|c|}
\hline & & \multicolumn{2}{|c|}{ Parent consanguinity } & \multirow[t]{2}{*}{ Total } & \multirow{2}{*}{$\begin{array}{c}\text { Chi- } \\
\text { Square } \\
\text { value }\end{array}$} & \multirow[t]{2}{*}{ P-value } \\
\hline & & No & $\begin{array}{l}\text { Other } \\
\text { relatives }\end{array}$ & & & \\
\hline \multirow{2}{*}{$\begin{array}{l}\text { Has your child ever been } \\
\text { hospitalized for a seizure }\end{array}$} & Yes & 14 & 8 & 22 & \multirow[t]{3}{*}{6.118} & \multirow[t]{3}{*}{0.019} \\
\hline & No & 71 & 11 & 82 & & \\
\hline Total & & 85 & 19 & 104 & & \\
\hline
\end{tabular}

\section{DISCUSSION}

The identification of risk factors for epilepsy by a city would make an essential contribution to the battle against epilepsy in that city as well as in other cities. Having the largest sample size in our city is important when assessing risk factors. According to residency, $67 \%$ of children lived in urban areas while $31.1 \%$ of children lived in rural areas; hence, the domicile has been recognized as a potential risk factor. Despite the fact that this was discovered while examining risk variables that were not determinate in the analysis of multivariate [17].

In our study, there was a weak association between children's head abnormalities and the development of epilepsy since the rate of head abnormality was 96.2 percentage and just 1.9 percentage had microcephaly [24].

Concerning gender, our study indicates that epilepsy is more common among females, it is about $51 \%$ compared to males who were $49 \%$. Similarly, another study indicated that the rate of influence in gender is generally close to the two genders, according to their findings., of Shiraz city in Iran, who are primarily male children in Shiraz were affected, then females and affected age 3 to 12 years old in the same research, Compared to children under 18 in Sulaimaniyah city in 104 cases of epilepsy in children 54 affected and exposure with epilepsy especially generalized seizure and 52 contains female with epilepsy and common in both genders, where the majority of epilepsy is male, but we are not found the child order in the family influence epilepsy more [18].

In another study, that has been done in Irbid city in Jordan where males are more likely to develop this condition than females, 124 are male and 76 females out of 200 patients are male and 76 are female compared to children in Sulaimaniyah city, and in Sulaimaniyah, the male 
rate is higher in this case [19].

Based on the patients'age of diagnosis, the current study showed that the majority of the case was diagnosed between ages 1-5 years old. They are about $46.5 \%$ and the minority of them was between 16-20 years old and it was 7.7\%, patients with febrile seizures had a lower risk, where $65.4 \%$ of participants had no febrile convulsion. The patients of the current study showed a background of febrile convulsions increased the likelihood of having epilepsy by just $36 \%$ [26].

The danger of epilepsy in febrile seizures individuals really was not uniform in which around $71.2 \%$ of patients who already had generalised seizures produced epilepsy, and having the highest incidence. Furthermore, females, older age, and having more seizures per year were linked to a worse quality of life. Thirty participants with the type of (Focal Seizure) have appeared while those of the unknown have appeared. We discovered that generalised seizures raised the chance of developing epilepsy by 75 times [21].

The high proportion of consanguineous among the epilepsy might be ascribed to the low percentage of individuals with epilepsy. However, we were unable to show statistical significance (it is only 18.9\%). We identified a statistical difference using the controlled experiment. The incidence of epilepsy following head trauma has been widely investigated in children 104 cases. This research shows a low incidence of epilepsy following head trauma, which is only $6.6 \%$. Similarly, children with a significant background of head trauma had a (6.6) fold risk of adverse epilepsy compared with the control group (93.4\%) through the current study [22].

Among epilepsy patients, there has been no history of CNS infection, such as meningitis. This finding is consistent with Al. Rajeh that reports 46 instances in Pakistan [23].

According to an Iranian study conducted on 90 Iranian children who had febrile seizure, 80 cases of them were febrile seizure, 53 were male and 37 children are female. For percentage, male $66 \%$ affected with febrile seizure in Iranian children and $34 \%$ affected with a febrile seizure while in Sulaymaniyah city children are more affected with generalized seizure, secondly affected with a febrile seizure. [24].

The risk of developing epilepsy increases, if there is a positive history of epilepsy, In our study, we compared our findings to those of other researchers in about.17,40,47,48. According to Iranian studies cited by Asadi-Pooya and Hojabri 14, living in a city increases one's risk of developing epilepsy by a factor of 3.34. Consanguineous nations like Turkey (50 instances), Jordan (15 cases), and Pakistan (15 cases) [25] may be expected to have higher rates of epilepsy [26].

Hypertension with cardiovascular illness before or during pregnancy increased the risk of epilepsy by 9 times when compared to the control. This result is consistent with findings of several studies that looked into this risk variable. Hypertension is known to be a major risk for possible quiet cerebrovascular resulting in seizures. Finally, despite the fact that only six people had newborn respiratory failure, the researchers did not find respiratory failure syndrome (RDS) or asphyxia could be a risk factor in the development of epilepsy [7].

Neonatal jaundice was previously identified as a risk factor exclusively in patients through mental retardation or cerebral palsy. Nevertheless, just a few studies have found a link between epilepsy and newborn jaundice, only 6 children had pathologic, and 100 children had no pathologic in the study [19].

We discovered, using univariate analysis, that neonatal jaundice raised the chance of developing epilepsy developing by 5.7 times. Despite the considerable sample size, this research has two major limitations. This is not a large-scale case-control study. Since it was focused on one group, it reflected that rather than the whole. If the witness's memory of the events is flawed while such data are collected, the resulting incidence may be larger than it really is [20].

At last, we discovered that the incidence rate differs by gender in two separate locations, with the incidence rate in Irbid and Shiraz being higher than in Sulaimaniyah due to the proximity of males. 


\section{CONCLUSION}

Conclusion: The majority of the patients were aged between six to ten while most of them was the middle child of their families. The results of the sample also showed that most of the children were diagnosed between ages one to five while most of the patients have a generalized seizure. On the other hand, there was a statistically significant association between febrile convulsion and family history of epilepsy depending.

Conclusion: Generalized Seizure is the most prevalent form in children aged one to five. Most of the attacked youngsters had their last seizure in 2020 and were not hospitalized. Most hospitalized youngsters NVD. Most of the children were born underweight with few if any neurological problems.

Pathological jaundice at birth is more common. No febrile convulsions or neonatal respiratory collapse. Less NICU admissions meant fewer infections. The majority of parents experience negative epilepsy. Most parents are healthy and aged 20 to 25 . Feverish convulsions had a statistically significant connection to epilepsy family history. Seizure hospitalization was linked to parent consanguinity

Recommendation: Health staff and professional maternity staff should not be excessively forced to pull the child's head during surgery or normal delivery; he or she is likely to cause nerve damage. Informing the child's parents about the disease so that they do not become worried about any neurological disorders, Ministry Of Health should instruct more parents whose children have this disorder in the nerve that is epilepsy so that they do not face disaster and be protected from falling immediately, our recommendation for nurses, neurology field and neurology specialists and neurologist when such child neuro-patients enter the hospital immediately and quickly and get the necessary treatment.

\section{REFERENCE}

[1] H.-J. Meencke, "Pathology of childhood epilepsies," Cleve. Clin. J. Med., vol. 56, pp. S111-S123, 1989.

[2] S. D. Shorvon and P. J. Farmer, "Epilepsy in developing countries: a review of epidemiological, sociocultural, and treatment aspects," Epilepsia, vol. 29, pp. S36-S54, 1988.

[3] S. D. Shorvon, "The etiologic classification of epilepsy," Epilepsia, vol. 52, no. 6, pp. 1052-1057, 2011.

[4] K. J. Eriksson and M. J. Koivikko, "Prevalence, classification, and severity of epilepsy and epileptic syndromes in children,” Epilepsia, vol. 38, no. 12, pp. 1275-1282, 1997.

[5] R. Guerrini, "Classification concepts and terminology: is clinical description assertive and laboratory testing objective?," Epilepsia, vol. 51, no. 4, pp. 718-720, 2010.

[6] U. Kramer, Y. Nevo, M. Y. Neufeld, A. Fatal, Y. Leitner, and S. Harel, "Epidemiology of epilepsy in childhood: a cohort of 440 consecutive patients," Pediatr. Neurol., vol. 18, no. 1, pp. 46-50, 1998.

[7] W. A. Hauser, "The prevalence and incidence of convulsive disorders in children," Epilepsia, vol. 35, pp. S1S6, 1994.

[8] P. W. Brazis, J. C. Masdeu, and J. Biller, "Localization in clinical neurology. 2011.” Philadelphia: Lippincott Williams \& Wilkins.

[9] W. Lammert and P. M. Gattone, "Stronger together-the Epilepsy Therapy Project and Epilepsy Foundation decide to merge. Our personal stories and reflections," Epilepsy Behav., vol. 25, no. 4, pp. 631-633, 2012.

[10] J. J. VasFe, J. Beaman, and C. C. SponarsFi, "RethinFing internal consistency in CronbachГs alpha," Leis. Sci., vol. 39, no. 2, 2017.

[11] H. Blbas, "Statistical Analysis for the Most Influential Reasons for Divorce between Men and Women in ErbilIraq," Oct. 2019.

[12] K. S. Taber, "The use of Cronbach's alpha when developing and reporting research instruments in science education," Res. Sci. Educ., vol. 48, no. 6, pp. 1273-1296, 2018.

[13] K. Aroian, N. Uddin, and H. Blbas, "Longitudinal study of stress, social support, and depression in married Arab immigrant women," Health Care Women Int., vol. 38, no. 2, pp. 100-117, 2017.

[14] H. Blbas and D. Kadir, "An Application of Factor Analysis to Identify the Most Effective Reasons that University Students Hate to Read Books," vol. 6, pp. 251-265, Oct. 2019.

[15] R. C. Blair and R. A. Taylor, "Biostatistics for the health sciences," 2007.

[16] S. Guo and M. W. Fraser, Propensity score analysis: Statistical methods and applications, vol. 11. SAGE publications, 2014.

[17] L. D. Cowan, A. Leviton, J. B. Bodensteiner, and L. Doherty, "Problems in estimating the prevalence of epilepsy in children: the yield from different sources of information," Paediatr. Perinat. Epidemiol., vol. 3, no. 4, pp. 386-401, 1989. 
[18] P. Katibeh, S. Inanloo, P. Katibeh, M. Rakhshan, H. H. Bakhodaei, and M. R. Alam, "Evaluation of the prevalence of prolonged QT syndrome in children with first unprovoked seizure," World Fam. Med. J. Inc. Middle East J. Fam. Med., vol. 99, no. 5832, pp. 1-4, 2018

[19] A. S. Daoud, A. Batieha, M. Bashtawi, and H. El-Shanti, "Risk factors for childhood epilepsy: a case-control study from Irbid, Jordan," Seizure, vol. 12, no. 3, pp. 171-174, 2003.

[20] S. Shinnar et al., "In whom does status epilepticus occur: age-related differences in children," Epilepsia, vol. 38, no. 8, pp. 907-914, 1997.

[21] J. F. Annegers, J. D. Grabow, R. V. Groover, E. R. Laws, L. R. Elveback, and L. T. Kurland, "Seizures after head trauma: a population study," Neurology, vol. 30, no. 7, pp. 683-683, 1980

[22] P. Pazzaglia and L. Frank-Pazzaglia, "Record in grade school of pupils with epilepsy: an epidemiological study," Epilepsia, vol. 17, no. 4, pp. 361-366, 1976.

[23] H. Aziz, "Gü vener A, Akhtar SW, Hasan KZ. Comparative epidemiology of epilepsy in Pakistan and Turkey: population-based studies using identical protocols," Epilepsia, vol. 38, no. 6, pp. 716-22, 1997.

[24] B. P. Hermann, "Quality of life in epilepsy," J. Epilepsy, vol. 5, no. 3, pp. 153-165, Jan. 1992, doi: 10.1016/S0896-6974(05)80134-3.

[25] A. Serdaroglu, S. Ozkan, K. Aydin, K. Gücüyener, S. Tezcan, and S. Aycan, "Prevalence of epilepsy in Turkish children between the ages of 0 and 16 years," J. Child Neurol., vol. 19, no. 4, pp. 271-274, 2004.

[26] A. Nicolosi, W. A. Hauser, E. Beghi, and L. T. Kurland, "Epidemiology of central nervous system infections in Olmsted County, Minnesota, 1950-1981,” J. Infect. Dis., vol. 154, no. 3, pp. 399-408, 1986. 